\title{
An Educational Intervention in Primary School Students Regarding Sun Protection: A Pilot Study
}

\author{
Saridi $\mathbf{M}^{1}$, Toska $A^{1}$, Rekleiti $\mathbf{M}^{1}$, Sarafis $\mathbf{P}^{2}$, Zoukas $L^{3}$, Souliotis $\mathbf{K}^{4 *}$ and Birbas $\mathbf{K}^{5}$ \\ ${ }^{1}$ Department of Nursing, General Hospital of Korinthos, Greece \\ ${ }^{2}$ Faculty of Nursing, Technological Educational Institute, Lamia, Greece \\ ${ }^{3}$ Department of Gynecology, General Hospital of Korinthos, Greece \\ ${ }^{4}$ Faculty of Social Sciences, University of Peloponnese, Korinthos, Greece \\ ${ }^{5}$ Faculty of Nursing, National and Kapodistrian, University of Athens, Greece
}

\begin{abstract}
Background: Epidemiological data have established a correlation between prolonged sun exposure during childhood and adolescence and occurrence of malign melanoma later in life. The aim of the present study was to investigate knowledge and attitudes of primary school students regarding sun protection measures and sun-related risks before and after an educational intervention.
\end{abstract}

Methods: It is a descriptive randomized pilot study of two stages with comparison of the results before and after an educational intervention. Sixty students aged 8-12 years from a coastal area participated in this study. Students first completed an anonymous questionnaire and after that took part in an intervention program. After 15 days the same students completed the questionnaire again. Data analysis was performed using the SPSS 17.0 and statistical significance was set to 0.05 .

Results: Students' awareness and knowledge level about sun-related risks and sun protection measures before the implementation of the intervention was satisfactory. Regarding sun protection factor, students' knowledge levels also increased and $55 \%$ of them answered correctly. The students' attitudes after the intervention showed some improvement, yet without any significant variation. There were no changes regarding the use of sunglasses and wearing appropriate clothing (hat, long-sleeve shirts, etc.). The proportion of children who used a sunscreen with SPF $30+$ was significantly higher in students after the intervention $(p<0.001)$. Sunburn incidence was found to be high. $35 \%$ of the students reported having at least one sunburn in the past summer. Children after the intervention had significantly higher knowledge scores compared to those before the program but the score in attitudes was not so high.

Conclusions: This pilot study showed that a similar intervention in a larger sample could increase and expand the students' knowledge about sun protection.

Keywords: Sun protection; Sun exposure; Sun block; Melanoma; Sunburn

\section{Introduction}

Solar light, entering the Earth's atmosphere, is filtered by the ozone layer which is at the stratosphere and absorbs most of the UVR by transforming it to heat. Ozone depletion in the last decades has resulted in a $1-3 \%$ annual increase in skin cancer cases worldwide $[1,2]$. Solar radiation risks are widely known and well-established in the literature. Solar radiation may have direct effects on the kin (redness, sunburn, etc.) that occur within hours or days after exposure, or long-term effects (squamous-cell carcinoma, basal-cell carcinoma, malign melanoma) that occur after prolonged exposure for many years [3].

Epidemiological data have established a correlation between prolonged sun exposure during childhood and adolescence and occurrence of malign melanoma later in life. Sunburn incidence in these age-groups is also a risk factor for skin cancer [4,5]. Children and adolescents are the main target groups of educational interventions in countries with high skin cancer incidence, such as Australia, New Zealand and USA. WHO and CDC have launched in the last decade similar programs that have been used as an example for other countries that wish to implement similar interventions too [6-9].

Relative studies and interventions have highlighted the students' awareness about sun-related risks and sun protection measures as well. They have also investigated the students' attitudes, beliefs and behaviours regarding sun exposure and sun protection. It has been documented that providing systematic and continuous information can change erroneous attitudes and lead to wiser behaviours [8-10].
The aim of the present study was to investigate knowledge and attitudes of primary school students regarding sun protection measures and sun-related risks before and after an educational intervention. It is a pilot study and its findings will be the basis for a full-scale study in the future. The present study will provide some useful insight about methodological problems and difficulties that may arise during planning, implementation, data collection and assessment of the intervention.

\section{Material and Methods}

\section{Research planning}

The present study is a pilot study that will be used as a guideline for a large-scale epidemiological study. It is a descriptive randomized study of two stages with comparison of the results before and after an educational intervention. One hundred and twenty students aged 8-12 years were our sample. They attended a school in the prefecture

*Corresponding author: Kyriakos Souliotis, Assistant Professor of Health Policy, Faculty of Social Sciences University of Peloponnese, Korinth, Greece, Tel: +30 27410 74991; Fax: +30 27410 74990; E-mail: soulioti@hol.gr

Received October 24, 2013; Accepted March 10, 2014; Published March 18 2014

Citation: Saridi M, Toska A, Rekleiti M, Sarafis P, Zoukas L, et al. (2014) An Educational Intervention in Primary School Students Regarding Sun Protection: A Pilot Study. Primary Health Care 4: 153. doi:10.4172/2167-1079.1000153

Copyright: (๑) 2014 Saridi M, et al. This is an open-access article distributed under the terms of the Creative Commons Attribution License, which permits unrestricted use, distribution, and reproduction in any medium, provided the original author and source are credited. 
of Korinthia which was later excluded from the final large-scale study. Response rate was $98 \%$ and the study took place from January 2009 until March 2009.

\section{Inclusion/Exclusion criteria -Ethics}

In this study, the sample comprised of elementary school students $(\mathrm{n}=120)$ aged 8-12 years. Their school was in an urban area and was later excluded from the final large-scale study. The students attended the Fourth, Fifth and Sixth grades. The Greek Pedagogical Institute granted approval. Informed consent was granted by the students' parents and the students themselves. Two non-Greek students had to be excluded due to poor Greek language skills. Strict anonymity was preserved. The school principal also granted permission. No banners or other advertising material was included in the intervention.

\section{Data collection}

The students had to complete a questionnaire that was administered to them before and after the intervention. In January 2009 students were administered the questionnaires for the first time. After that, the educational intervention took place, and then, in March, the same questionnaire was re-administered to them, in order to assess any changes in their awareness and attitudes regarding sun protection. Completion of the questionnaires took one school hour during the 'Flexible Zone' hours. The intervention took place after the collection of the questionnaires, and the researchers came back to the school 40 days later and administered the same questionnaires in order to assess the intervention's effectiveness.

\section{Instruments}

Questionnaire: The literature review did not provide us with a questionnaire specifically designed for this particular age-group (812 years old students). Consequently, the researchers had to develop a special questionnaire drawing from the Intersun programme, developed by the WHO [8]. The relevant Australian programme (Sun Smart) also played a role in the development of our instrument [7].

The questions, apart from the demographics, aimed at assessing the students' knowledge about sun-related risks and sun protection measures. The questionnaire included 21 items. Demographics included age, gender, nationality, place of residence and distance from the beach. Personal data that are important for someone's attitude towards sun protection, such as complexion, eye colour, freckles and moles on the skin were also included. The students' knowledge about sun-related risks and sun protection measures were also investigated. The biggest part of the questionnaire (items 10-21) was about daily sunprotection, especially in the summer. The questionnaire had also been pilot-tested on 50 same-age students and all necessary amendments had been made. Internal cohesion reliability was assessed by Cronbach's alpha which was 0.79 . Alpha reliability of the attitude-related items was $\mathrm{rs}=0.78$. Face validity was deemed satisfactory by four specialists (one statistician, two university professors and one $\mathrm{PhD}$ candidate in Health Education).

Educational intervention: The intervention programme was designed along the lines of the Australian SunSmart [7] programme, which is tailored for this particular age group. It included a presentation about positive and negative effects of sun radiation on humans and extensive information about ozone and its protective role against UVR. After that, students were informed in detail about sun protection measures. The intervention focused on the correct sun protection factor a sunscreen for children should have, and on applying correctly the sunscreen.

\section{Statistical analysis}

Means and standard deviations were used for the description of quantitative variables. Absolute $(\mathrm{N})$ and relative (\%) frequencies were used for the qualitative variables. In order to compare quantitative variables among two groups, Student's t-test was used, whereas for comparison among three or more groups parametric analysis (ANOVA) was used. Significance levels were bilateral and statistical significance was set to 0.05 . The SPSS 17.0 software was used for the analysis.

\section{Results \\ Demographics}

The average age of the sample $(n=120)$ was 9.9 years $( \pm 1.1)$, while $58 \%(\mathrm{n}=75)$ were females and $42 \%(\mathrm{n}=50)$ were males. Moreover, $80 \%$ $(n=24)$ of the students were Greek, while $20 \%(n=24)$ were of nonGreek nationality. 26\% ( $n=32)$ of the participants belonged to the highrisk group. More specifically, the high-risk group included children who had four out of five high-risk characteristics (fair complexion, light-coloured eyes or hair, freckles and moles) (Table 1).

\section{Awareness and knowledge}

Students' awareness and knowledge level about sun-related risks and sun protection measures before the implementation of the intervention was satisfactory. After the intervention, there was an overall increase in knowledge levels. More specifically, before the intervention, $82 \%$ of the participants knew that the sun's heat is at its peak between 10.00 a.m. and 16.00 p.m., $92 \%$ were aware that sunscreen can help prevent sunburns and $75 \%$ knew that excessive sun exposure may cause skin and eye damage. Yet only $25 \%$ of them knew that sunscreens for children should have a sun protection factor of 50 . After the implementation of the programme, there was a positive shift in the students' knowledge levels. More specifically, $91 \%$ of the students knew when the sun's heat is at its peak, 95\% had learned that sunscreen can prevent sunburns and $85 \%$ knew that excessive sun exposure may lead to skin and eye damage. Regarding sun protection factor, students' knowledge levels also increased and $55 \%$ of them answered correctly.

There was also a significant difference regarding knowledge levels among children of different age. More specifically, after Bonferroni Correction was applied, students aged 10 years outscored both students aged less than 9 years $(\mathrm{p}<0.001)$, and students aged $9-10$ years $(\mathrm{p}<0.001)$, as well.

Also there was no statistically significant difference regarding knowledge levels between females and males. The males' percentage of

\begin{tabular}{|l|c|c|c|}
\hline \multirow{2}{*}{ High-risk group } & & $\mathbf{N}$ & $\%$ \\
\hline \multirow{2}{*}{ Your complexion is } & No & 88 & 74 \\
\hline \multirow{2}{*}{ Your eye-colour is } & Fair, prone to sunburns & 32 & 26 \\
\hline & Darker, sunburns are rare & 90 & 75 \\
\hline \multirow{2}{*}{ Your hair-colour is } & light & 24 & 20 \\
\hline \multirow{2}{*}{ Do you have freckles on your face/body? } & dark & 96 & 80 \\
\hline & light & 28 & 23 \\
\hline Do you have any moles on your facel & dark & 92 & 77 \\
\cline { 2 - 4 } body? & No & 88 & 80.6 \\
\hline \multirow{2}{*}{ Table 1: Individual characteristics. } & 32 & 19.4 \\
\hline & Yes & 88 & 74 \\
\hline
\end{tabular}


overall right answers increased significantly ( $2.8 \pm 0.9$ vs $3.2 \pm 0.9)$, and so did the females' right answers $(2.9 \pm 0.8$ vs $3.4 \pm 0.8)$.

\section{Attitudes}

The students' attitudes after the intervention showed some improvement, yet without any significant variation (Table 2). It seems that there was a significant difference regarding applying sun protection measures before and after the intervention (Table 3). More specifically, children after the intervention said they applied sun protection measures more often than before the programme.

There were no changes regarding the use of sunglasses and wearing appropriate clothing (hat, long-sleeve shirts, etc.). The proportion of children who used a sunscreen with Sun Protection Factor (SPF) 30+ was significantly higher in students after the intervention $(\mathrm{p}<0.001)$. On the other hand, sunscreen use was higher among students when asked before the intervention ( $78.2 \%$ vs $65.5 \%)$. The percentage of children who re-applied sunscreen after getting out of the sea was much higher after the intervention, while when asked if they continue to apply sunscreen even after getting a tan the percentage was significantly lower among children when asked after the intervention ( $29.7 \%$ vs $54.8 \%)$.

In what regards the children's activities and protection measures

\begin{tabular}{|l|c|c|c|c|c|}
\hline \multirow{2}{*}{} & \multicolumn{4}{|c|}{ Measurements } & \multirow{2}{*}{ P Student's t-test } \\
\cline { 2 - 5 } & \multicolumn{2}{|c|}{ Before } & \multicolumn{2}{c|}{ After } & \\
\hline mean & SD & mean & SD & $<0.001$ \\
\hline
\end{tabular}

Table 2: Overall attitude before and after intervention.

\begin{tabular}{|c|c|c|c|c|}
\hline & \multicolumn{2}{|c|}{ Percentage } & \multirow{3}{*}{$\begin{array}{c}P \\
\text { Pearson's } \\
x^{2} \text { test }\end{array}$} \\
\hline & & \multirow{2}{*}{\begin{tabular}{c|} 
Before \\
$\%$
\end{tabular}} & \multirow{2}{*}{$\begin{array}{c}\text { After } \\
\%\end{array}$} & \\
\hline & & & & \\
\hline \multirow{2}{*}{$\begin{array}{l}\text { Do you wear a hat when } \\
\text { under the sun? }\end{array}$} & Always & 33.1 & 42.3 & $<0.001$ \\
\hline & & & & \\
\hline \multirow{2}{*}{$\begin{array}{l}\text { Do you wear long trousers } \\
\text { and long-sleeve shirts when } \\
\text { under the sun? }\end{array}$} & Always & 18.7 & 7.9 & $<0.001$ \\
\hline & & & & \\
\hline \multirow{2}{*}{$\begin{array}{l}\text { Do you usually stay in the } \\
\text { shade when at the beach? }\end{array}$} & Always & 45.2 & 49.0 & 0.049 \\
\hline & & & & \\
\hline Do you wear sun-glasses? & Always & 38.5 & 33.9 & 0.009 \\
\hline Do you use sunscreen? & Always & 64.0 & 75.3 & $<0.001$ \\
\hline \multirow{4}{*}{$\begin{array}{l}\text { What is the SPF of your } \\
\text { sunscreen? }\end{array}$} & $\begin{array}{l}\text { I never used one/ } \\
\text { Lower than } 15\end{array}$ & 8.8 & 9.0 & $<0.001$ \\
\hline & 15 & 15.3 & 14.5 & \\
\hline & 30 & 29.7 & 54.8 & \\
\hline & I do not know & 46.2 & 21.6 & \\
\hline \multirow{2}{*}{$\begin{array}{l}\text { Do you re-apply sunscreen at } \\
\text { the beach? }\end{array}$} & Every 2 hours & 30.5 & 32.5 & 0.037 \\
\hline & & & & \\
\hline \multirow{2}{*}{$\begin{array}{l}\text { When tan, do you use keep } \\
\text { using sunscreen? }\end{array}$} & Always & 59 & 52.6 & $<0.001$ \\
\hline & & & & \\
\hline \multirow{3}{*}{ Do you like to get a tan? } & No & 57.4 & 34.2 & $<0.001$ \\
\hline & Yes & 26.5 & 39.5 & \\
\hline & I don't care & 16.1 & 26.3 & \\
\hline
\end{tabular}

Table 3: Attitude before and after intervention. before and after the intervention, when asked after the programme, they said they took more protection measures compared to before the programme. More specifically, before the intervention children said that they used to take more protection measures compared to their answers after the intervention, mainly when they play at the park $(22.5 \%$ vs $20.1 \%$ ), during Physical Exercise (P.E.) class (17\% vs 15.6\%) and when they go hiking to the mountain $(15.2 \%$ vs $1.6 \%)$. Even when they go the beach/pool, it seems that more children used to take protection measures (67.5\% vs $66.2 \%$ ) before the intervention, although this does not seem to be statistically significant $(\mathrm{p}=0.092)$.

Sunburn incidence was found to be high. $35 \%$ of the students reported having at least one sunburn in the past summer. This answer was not assessed after the intervention, since it wasn't summer yet and because this was a pilot-study in order for the intervention to be standardized.

\section{Correlations}

There was a significant difference in knowledge levels in accordance with a child's place of residence and its distance from the beach. After Bonferroni Correction was applied, it was found that students who lived $15-20 \mathrm{~km}$ away from the beach had lower scores compared to those who lived $0-5 \mathrm{~km}, 10-15 \mathrm{~km}, 20$ and over $\mathrm{km}$ away from the beach $(\mathrm{p}<0.001$, $\mathrm{p}=0.005$ and $\mathrm{p}=0.015$ respectively). Moreover, students living in urban areas outscored those who lived in semi-urban areas (2.9 \pm 0.9 VS $2.7 \pm$ 0.8. $\mathrm{P}=0.001$, Pearson's $\mathrm{x}^{2}$ test).

The correlation between attitude and gender showed that both males and females had slightly worse attitudes towards protection measures after the intervention. Specifically, males and females do not usually wear a hat and appropriate clothes $(\mathrm{p}<0.001)$.On the other hand, use of sunscreen with SPF $30+$ showed an important $(\mathrm{p}<0.001)$ increase (males: $33.2 \%$ vs $47.2 \%$; females: $26.2 \%$ vs $62.9 \%$ ). Re-application of sunscreen was also higher. In this case, males reported they re-applied sunscreen every two hours, after the intervention, $(30.7 \%$ vs $33.8 \%$, $\mathrm{p}=0.030)$, but females did not show any significant change $(30.2 \%$ vs $31.2 \%, \mathrm{p}=0.337)$.

Correlation between knowledge and age showed that younger students had gained much more knowledge after the intervention. It was also found that children less than 9 years of age took protection measures when playing at the park $(15.1 \%$ vs $23.4 \%)$ and when they used to go to the mountain ( $8.4 \%$ vs $14 \%$ ), compared to children 10 years and older. Males took significantly $(\mathrm{p}<0.001)$ less protection measures than females when they used to go to the beach $(65.3 \%$ vs $73.5 \%)$ and during P.E. class (13.8\% vs $21.7 \%)$.

Correlation between attitudes and nationality showed that Greek students had had better sun-related attitude than students of non-Greek nationality. Also, students that did not belong to a high-risk group had had better attitude regarding protection measures.

Finally, it was found that children after the intervention had significantly higher knowledge scores compared to those before the programme, regardless of whether they belonged to a high-risk group or not.

Regarding the high-risk group, there was a difference in using protection measures among students before and after the intervention. More specifically, when asked after the intervention, high-risk children said that they used to wear less often long trousers ( $19.1 \%$ vs $2.7 \%)$, sunglasses $(38.4 \%$ vs $31.4 \%)$ and apply sunscreen $(77.5 \%$ vs $65.9 \%)$ compared to their answers before the intervention. On the other hand, after the intervention, high-risk students said that they would 
use sunscreen with SPF $30+$ much more than before the intervention $(27.2 \%$ vs $60.6 \%)$. Similarly, after the intervention the percentage of high-risk students who would re-apply sunscreen every two hours was much higher than before ( $28.3 \%$ vs $43.2 \%)$. Also, after the intervention the percentage of high-risk students who wanted to be tan, was again higher $(25.4 \%$ vs $51 \%)$.

\section{Discussion}

The present study investigated the changes in knowledge and attitudes of students after an educational intervention. Also, it examined whether the questionnaire was easily understood by the students, in order to be administered to a larger sample without any significant methodological problems.

The implementation of prevention and educational programmes within primary education is an important part of Health Education in many countries. In Greece, some health promotion programmes have taken place during the last years, although it seems that sun protection is not a top priority for the Ministry of Health yet. Nevertheless, sun protection is a priority for many other countries, and also for the $\mathrm{WHO}$ and the CDC, and multiple prevention programmess have been launched and taken place in schools [6-9].

The international literature has established that systematic and well-coordinated programmes that focus on large population groups can have better results than sporadic, isolated interventions. The 8-12 age-group seems to be the best option for educational interventions aiming at knowledge improvement and healthier behaviours through attitude change [11-13].

Our demographic results showed that the number of males and females was almost the same. Almost $20 \%$ of the participants were of non-Greek nationality, something that shows that Greece has become essentially multicultural. In the larger study, it is expected that knowledge and attitudes will vary according to nationality, as well. This hypothesis is based on the assumption that other characteristics (e.g. phototype) and different clothing in other cultures may have an effect on the foreigners' attitude towards sun exposure and sun protection measures [14-16].

The students' knowledge level was high even before the intervention, but it got significantly higher after the intervention, something that confirms that this programme could be useful for a larger student sample. Our findings are in agreement with those of other studies that have reported high knowledge scores regarding sun protection measures [15-20]. Also, although before the intervention the students' knowledge about sun protection factors was low $(25 \%)$, after the intervention it increased to $55 \%$, since the programme was specifically aiming at enhancing knowledge about SPF. Similar studies from Spain, the US, New Zealand and Turkey have found lower knowledge levels regarding SPF [21-24]. Several international studies have shown an improvement regarding choosing the appropriate sunscreen, similarly to the present study. Finally, older age students seem to have higher knowledge levels, as expected, since knowledge accumulates over time [10-15].

The students' attitude showed some improvement after the intervention, although not a very significant one. Nevertheless, this was an encouraging sign for the present study. This finding could be attributed to the fact that new and healthier behavioral patterns cannot be adopted by children just on account of more knowledge, since family, peer and school influence play an important role in adopting wiser behaviors, as other studies have also shown $[15,18,25]$.

Sunburn incidence is a well-known risk factor for sun-related damages, according to the literature. In the present study, a significant percentage of the participants (35\%) reported having at least one sunburn in the past summer. Other studies have also found similar percentages [20,26-30]. In the present study, it wasn't feasible to assess whether the intervention had reduced sunburn incidence, because it took place before the summer. The forthcoming full-scale study will include a full assessment. Similar interventions worldwide have been shown to reduce sunburn incidence among young person's [26,28,31-33].

Distance between place of residence and the beach was also found to be a significant factor affecting knowledge and attitudes. Students who lived relatively away from the beach in semi-urban areas had, in general, low knowledge levels and did not take sun protection measures, compared to students who lived closer to the beach and had more frequent exposure to the sun. On the other hand, children from rural areas have prolonged exposure to the sun because they may help their parents at the farm or play outdoors $[34,35]$.

This pilot study showed that educational interventions yield better results when implemented at a young age, a finding confirmed by other international studies. Interventions should be aimed at previously documented knowledge gaps and deficiencies and try to accomplish specific targets. The main target of the present study was to enhance the students' knowledge about sun protection factors (SPF), appropriate use of sunscreens and sun-related risks. The long-term target was to make students adopt healthier attitudes and behavior towards sun exposure. The present pilot study used a small sample and was followed by a full-scale study with a sample of 5000 students.

\section{Conclusion}

This pilot study showed that a similar intervention in a larger sample could increase and expand the students' knowledge about sun protection. The study was also used as a means of assessing the questionnaire and, in this respect, no methodological problems arose during all the stages of the study.

It is noteworthy that such interventions should be systematic and continuous, since a simple one-time presentation cannot expand the students' knowledge. Systematic up-to-date information is required, and developing interventions specifically designed for each age-group is also essential. In order for such interventions to be successful, social, school and family environment should be included and should actively participate. Parents and teachers should also be informed, since students are by and large influenced by family and school environment.

\section{References}

1. Zepp RG, Erickson DJ 3rd, Paul ND, Sulzberger B (2011) Effects of solar UV radiation and climate change on biogeochemical cycling: interactions and feedbacks. Photochem Photobiol Sci 10: 261-279.

2. Zerefos CS, Meleti C, Balis DS, Bais AF, Gillotay D (2000) On changes of spectral UV-B in the 90's in Europe. Advances in Space Research 26: 19711978.

3. Arola A, Lakkala K, Bais A, Kaurola J, Meleti C, et al. (2003) Factors affecting short- and long-term changes of spectral UV irradiance at two European stations. Journal of Geophysical Research 108.

4. Armstrong BK, Kricker A (2001) The epidemiology of UV induced skin cancer. J Photochem Photobiol B 63: 8-18.

5. Siegel R, Naishadham D, Jemal A (2012) Cancer statistics, 2012. CA Cancer J Clin 62: 10-29.

6. Cancer Society of New Zealand (2006) Sample Sun Protection Policy fo Primary Schools. Wellington, New Zealand: Cancer Society of New Zealand.

7. Anti-Cancer Council of Victoria (2002) SunSmart Program 2003-2006. Victoria Anti-Cancer Foundation of Victoria: 1-48. 
Citation: Saridi M, Toska A, Rekleiti M, Sarafis P, Zoukas L, et al. (2014) An Educational Intervention in Primary School Students Regarding Sun Protection: A Pilot Study. Primary Health Care 4: 153. doi:10.4172/2167-1079.1000153

8. World Health Organization (2003) Sun Protection and Schools: How to Make a Difference. Geneva: World Health Organization.

9. CDC (2003) Counseling to prevent skin cancer: recommendations and rationale of the US Preventive Services Task Force. MMWR 52: 13-17.

10. Dadlani C, Orlow SJ (2008) Planning for a brighter future: a review of sun protection and barriers to behavioral change in children and adolescents. Dermatol Online J 14: 1

11. Horsley L, Charlton A, Waterman C (2002) Current action for skin cancer risk reduction in English schools: pupils' behaviour in relation to sunburn. Health Educ Res 17: 715-731.

12. Buller DB, Buller MK, Reynolds KD (2006) A survey of sun protection policy and education in secondary schools. J Am Acad Dermatol 54: 427-432.

13. Eakin P, Maddock J, Techur-Pedro A, Kaliko R, Derauf DC (2004) Sun protection policy in elementary schools in Hawaii. Prev Chronic Dis 1: A05.

14. Saraiya M, Hall HI, Uhler RJ (2002) Sunburn prevalence among adults in the United States, 1999. Am J Prev Med 23: 91-97.

15. de Vries H, Lezwijn J, Hol M, Honing C (2005) Skin cancer prevention: behaviour and motives of Dutch adolescents. Eur J Cancer Prev 14: 39-50.

16. Hill D, Dixon H (1999) Promoting sun protection in children: rationale and challenges. Health Educ Behav 26: 409-417.

17. Dixon H, Borland R, Hill D (1999) Sun protection and sunburn in primary school children: the influence of age, gender, and coloring. Prev Med 28: 119-130.

18. Saridi M, Toska A, Rekleiti M, Wozniak G, Liachopoulou A, et al. (2012) Sunprotection habits of primary students in a coastal area of Greece. J Skin Cance 2012: 629652 .

19. Piperakis SM, Papadimitriou V, Piperakis MM, Zisis P (2003) Understanding Greek primary school children's comprehension of sun exposure. Journal of Science Education and Technology 12: 135-142.

20. LaBat K, De Long M, Gahring SA (2005) A Longitudinal Study of Sun-Protective Attitudes and Behaviors. Family and Consumer Sciences Research Journal 33: $240-254$

21. Gilaberte Y, Alonso JP, Teruel MP, Granizo C, Gállego J (2008) Evaluation of a health promotion intervention for skin cancer prevention in Spain: the SolSano program. Health Promot Int 23: 209-219.

22. Wright C, Reeder Al, Gray A, Cox B (2008) Child sun protection: sunrelated attitudes mediate the association between children's knowledge and behaviours. J Paediatr Child Health 44: 692-698.

23. Ergul S, Ozeren E (2011) Sun protection behavior and individual risk factors of
Turkish Primary School Students associated with skin cancer: a questionnairebased study. Asian Pac J Cancer Prev 12: 765-770.

24. Geller AC, Cantor M, Miller DR, Kenausis K, Rosseel K, et al. (2002) The Environmental Protection Agency's National SunWise School Program: sunprotection education in US schools (1999-2000). J Am Acad Dermatol 46 683-689.

25. Geller AC, Rutsch L, Kenausis K, Selzer P, Zhang Z (2003) Can an hour or two of sun protection education keep the sunburn away? Evaluation of the Environmental Protection Agency's Sunwise School Program. Environ Health 2: 13

26. Richtig E, Jung E, Asbäck K, Trapp M, Hofmann-Wellenhof R (2009) Knowledge and perception of melanocytic nevi and sunburn in young children. Pediatr Dermatol 26: 519-523.

27. Cokkinides V, Weinstock M, Glanz K, Albano J, Ward E, et al. (2006) Trends in sunburns, sun protection practices, and attitudes toward sun exposure protection and tanning among US adolescents, 1998-2004. Pediatrics 118: 853-864.

28. Davis KJ, Cokkinides VE, Weinstock MA, O'Connell MC, Wingo PA (2002) Summer sunburn and sun exposure among US youths ages 11 to 18: national prevalence and associated factors. Pediatrics 110: 27-35.

29. Lowe JB, Borland R, Stanton WR, Baade P, White V, et al. (2000) Sun-safe behavior among secondary school students in Australia. Health Educ Res 15: 271-281.

30. Girgis A, Sanson-Fisher RW, Tripodi DA, Golding T (1993) Evaluation of interventions to improve solar protection in primary schools. Health Educ $Q$ 20: $275-287$

31. Richards R, McGee R, Knight RG (2001) Sunburn and sun protection among New Zealand adolescents over a summer weekend. Aust N Z J Public Health 25: 352-354

32. Milne E, Jacoby P, Giles-Corti B, Cross D, Johnston R, et al. (2006) The impact of the kidskin sun protection intervention on summer suntan and reported sun exposure: was it sustained? Prev Med 42: 14-20.

33. Banks BA, Silverman RA, Schwartz RH, Tunnessen WW Jr (1992) Attitudes of teenagers toward sun exposure and sunscreen use. Pediatrics 89: 40-42.

34. Aalborg J, Morelli JG, Mokrohisky ST, Asdigian NL, Byers TE, et al. (2009) Tanning and increased nevus development in very-light-skinned children without red hair. Arch Dermatol 145: 989-996.

35. SaridiM, Bourdaki E, Rekleiti M (2014) Young students' knowledge about sun protection and its relation with sunburn incidence. A systematic review. Health Science Journal 8: 4-21. 